\title{
The way forward for the Land Registry
}

\author{
by Louis Charlebois
}

E-conveyancing is currently the subject of a consultation paper by the Land Registry, and a second paper deals with new Land Registration Rules. This article puts these papers in context.

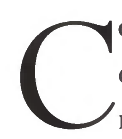
onveyancing, in computer terms communication and registration. As matters stand now in a paper world, the Land Registry does not become involved in the conveyancing process until instruments are submitted for registration, searches of its records apart. To put the current paper transactions involving the Land Registry on computer means that the practitioner would create an electronic dealing and send it to the Land Registry in accordance with an approved electronic format. The paper trail would stop with the practitioner, who would have to keep the paper record for examination in case of error or dispute. The quality of information on the Register is maintained now by the inspection of dealing at the Land Registry individually before it is approved for registration. Will each practitioner under e-conveyancing be allowed to change the Register unilaterally without review by the staff of the Land Registry? And who will be able to alter the Register? These questions are key to the Land Registry's role in econveyancing, but the consultation papers make no comment on them.

The Land Registry has no expertise in conveyancing, because conveyancing does not come within its jurisdiction. The Land Registry is responsible for land registration, and the Law Society for conveyancing. But the Law Society is not in the loop. There are two forewords to the e-conveyancing consultation paper contributed by the Lord Chancellor and the Chief Land Registrar, but none from the Law Society. The Lord Chancellor sets policy, and one can only assume that he directed the Chief Land Registrar to develop e-conveyancing, rather than assigning the task to the Law Society. It would be unfortunate if the seller's pack, the contract, and the chain, not now the subject of registration, were to be determined by a Land Registry bureaucracy without full consultation and approval from the Law Society.

Facilitating simultaneous completion and registration is excellent - but after all, registration is what the Land Registry is there for. Under the new Land Registration Rules, the elimination of land and charge certificates is a good step, if late in coming. A land certificate indicates the right of the person lodging a dealing to deal with the land. Research in Australia in the sixties showed that it also was significant in enabling fraud against the Register. It should also be pointed out that the consummate documents produced here are expensive. And by the way, only HMLR would dream of sending an original registration document, a mortgage, back to the people with the least need to be further advised of its terms - the lender. .

As long as the Registry ignores its primary task of completing the Register, registration will be detrimentally affected by unregistered land. The e-conveyancing paper says that a 'provisional' title will issue for unregistered land apparently as quickly as an e-title will issue for registered land. But the new Land Registry rules do not reflect this. The Act provides for qualified title, but the provision is almost never used. It should be available routinely for every first registration, certainly where registration is compulsory because of a trigger. With less xenophobia and more research, establishing rules for qualified title would not be difficult and should have been done in the new rules. And creating easements by amending the plan would be a major advance...

\section{PROBLEMS WITH THE CURRENT SYSTEM}

What is wrong with the record of registered land held by HM Land Registry? Lots, is the simple answer. The 1925 Act upon which the Land Registry is established presumed that the Chief Land Registrar knew how to maintain a register of land and simply directed him to continue to do so. The Act did not give him directions on how to do it. It does not take too much reflection to realise that any record of land ownership must have two databases, one being a text or document record that tells who owns the land and any restriction on that ownership, and the other describing the extent of that ownership.

The rules authorised by the Act make two references to the graphic parcel record to be maintained. It must be indexed according to the Ordnance Survey, and it is called the general map. The problem is that the general map, 
although absolutely essential to the rational administration of a land registry, and required by law, has never been created.

The scale used by land surveyors for urban land parcels ranges from 1:100 to $1: 400$. The Ordnance Survey scale is $1: 1250$ or $1: 2500$. In practice when the Land Registry receives a survey of a parcel for registration, it uses the survey to identify an appropriate Ordnance Survey parcel and highlights that Ordnance Survey parcel in red. This means that the parcel record maintained by HM Land Registry has been reduced in scale from 1:100 (to 1:400) to $1: 1250$ or $1: 2500$. And that in turn means that the record of the boundary is made substantially wider in relation to the parcel. That wider boundary can make it impossible to tell from the boundary record maintained by HMLR whether your fence, your hedge - even your driveway - is within or outside the boundary to your land. There is no need for this imprecision. Modern computer technology can easily store boundary information with survey precision.

To the best of my knowledge no record is kept of how many boundary disputes arise each year, and it would in any event be difficult to arrive at an exact number because many do not go beyond an argument with a neighbour. However, boundary disputes are a major cause of enquiry at Land Registries, and Registry staff responds with standard reply to the effect that they do not have sufficient information to allow them to resolve the dispute. On the information available to me, the number of boundary disputes arising each year would appear to be embarrassingly large.

The failure of the Land Registry to produce a reliable parcel record has resulted in more serious problems than boundary disputes. The nation needs a geographical information system (GIS), which could provide landrelated information with precision for all regions of the country. That information could be surface and subsurface. It could show terrain (as well as land use and surface pollution, such as chemical spills), the water table, contaminants in the water, and mineralisation. It could also be used to show forests, thereby providing an important tool for forest management, and help to control plant and animal disease.

GIS information can and should match a surface ownership grid. Every database requires a unique identifier; otherwise the data cannot be sorted. There is only one rational choice for the unique identifier to be applied to a national GIS - the legal parcel, like the one a house is built on.

Who has the job of maintaining the record of legal parcels? The Land Registry, by virtue of the 1925 Act which gave the task of running the 'register of title to freehold and leasehold land' to the Chief Land Registrar. The 'register of land' was not defined, and nor was the
Registrar given directions on how to run it. But clearly, it required two main components: a text or document record that informs you who owns the land and any restrictions on that ownership, like easements, covenants or a mortgage; and the plan or parcel record that gives you the physical extent of what you own represented by the boundaries of your parcel. The detail and information of a survey plan is totally lost at the miniscule scale of the Ordnance Survey. It makes a postage stamp look as if it belongs in the land of giants.

\section{NEED FOR A GENERAL MAP}

Why do we need a general map? The answer is to preserve the precision, detail and information provided by a survey. We are not alone. The Land Registration systems in the countries all around us maintain such a parcel record. Why should our system fall so dramatically below their standards? The systems around us come under different names: for example Systeme des Hypotheques in France, and Grundbuch in Germany and Austria (this term also applies to the territory that used to form a larger Germany and a much larger Austria. The Scandinavian countries have a similar system, while Australia, New Zealand, most of the provinces of Canada, some of the United States of America, Malaysia, Singapore and Morocco operate a Torrens system which is based on the Grundbuch system but is easier, cheaper and faster to use. The genius of the Dutch approach is that it has a Grundbuch survey but operates as a Torrens system, and works very well. We have a Torrens system, although the Land Registry does not acknowledge that. This lack of understanding may be the reason that the Registry stands alone both in Western Europe and among Torrens systems in not maintaining a precise, accurate parcel record.

The bottom line is that there is no point in maintaining an imprecise record when a precise record can be achieved. When the Land Registry receives a copy of a survey, it should not use it simply to locate an Ordnance Survey parcel. The detail should be recorded as part of the general map. There is much survey available to the Registry just for the asking and therefore at no cost: the general map thus created would progress from zero survey accuracy to full survey accuracy, because each survey recorded tightens up the boundary record of contiguous parcels. Many lunacies could be avoided, and the pre-build and post build concept could be abandoned. A survey of the proposed development could be filed with the Registry, the survey copied into the general plan, and parcel numbers allocated. The parcel number would be the title number. British builders know how to build within surveyed boundaries. The buyer of a new house then has title/parcel 12345 transferred to him. He does not need to go through the delay, cost, difficulty and uncertainty of a transfer of part.

The Registry must move as quickly as possible to the 
completion of a general map for all of England and Wales (the actual jurisdiction of the Land Registry).

It makes no sense at all to require you and me to register our land at the Registry when public authorities are not required to register theirs. There is a critical shortage of land for residential use in much of the country: a rationally compiled record of all land in a comprehensive database at survey accuracy would be of great assistance to anyone seeking available land for housing development.

To be valuable, the parcel map must be comprehensive and therefore needs to include all of the land in England and Wales. This task needs to be completed as soon as possible. It has already begun in the form of the Land Registry's adopted approach of 'sweeping in'. This is the basis of the policy of 'triggers' - dealing with land that requires you to register it. Almost anything you do with your land, if it is not yet registered, will require you to register it. 'Sweeping in' refers to the policy of including all parcels in the parcel record.

Unfortunately, the policy of sweeping in is not being followed. There is no requirement for public land and land owned by local and central government to be registered, and so registration is not taking place. This means that the most obvious source of land for new residential development is not on a central database. Every year there seems to be new instances of one local government authority or another acquiring land it already owns because it has no adequate record showing ownership.

The argument from the Land Registry is that, as with registration required of ordinary landowners through a trigger, the Registry must be paid for the registration. The second and third largest Torrens land registry systems following HMLR are Ontario and New South Wales. Both of these systems bring in first registrations at no charge. I know that in New South Wales it was calculated before the policy was adopted that dealings with land subsequent to its first registration would provide on average sufficient income to the registry to make that first free registration hugely profitable. That principle, applied here, would be both feasible and desirable because it would encourage first registrations at no charge, both through the trigger process and the registration of public land, to advance the completion of a comprehensive parcel database.

Every conveyancer knows the difficulty of meeting the requirement of establishing evidence of ownership to a good root of title required by a trigger when key documents are missing. The New South Wales solution to this was to ask for the best evidence available and then to issue a 'qualified title'. This did not inhibit mortgage lending, and the qualification was removed with the passage of a time limitation. Put simply, if the owner's claim to ownership appeared genuine on the evidence available, title was issued in his name. If anyone objected to that title and had evidence to support the objection, the title could be changed. Almost no one objected, so very few titles had to be changed and the rate at which the task of first registration could be accomplished grew exponentially. The New South Wales experience can, should and must be adopted here.

Meanwhile, because the Land Registry has failed to provide the required parcel record, the occasion has arisen for two other groups to move in to fill the gap - NLIS (the National Land Information System), and the National Land and Property Gazetteer. Neither can function without a parcel map based on ownership - precisely the same requirement as that of the Land Registry. But their parcels are not integrated with each other, and are not integrated with the Land Registry parcel record. Therefore a substantial expenditure of time and resources is taking place to develop three competitive authoritative parcel records. This is a descent into Babel. Recently I visited Slovenia to see their system of Land Registration, now in the midst of a reform programme. In two years time, when their programme is complete, they will have a system of land registration that will leave that of England and Wales in the dust. How unnecessary when the staff and the resources are available to get it right.

The Land Registry has taken on the task of developing electronic conveyancing, but unfortunately the Registry has neither expertise nor experience in conveyancing. It should be the task of the Law Society to move electronic conveyancing forward, albeit in co-operation with the Land Registry. One serious problem to be addressed is the gap between completion and registration. If the Land Registry could bend its efforts to bring about simultaneous completion and registration, it would make a huge contribution toward more secure, and timely, conveyancing. But this cannot happen unless the land is registered in the first place, and the only way we can be sure of land being registered is by completing the 'sweeping in' process.

\section{CONCLUSION}

The completion of the parcel record for England and Wales at survey accuracy at the Land Registry should be a matter of national priority. Let us stop the apparent turf war between local government and the Land Registry and move immediately towards the registration of all government and public authority land as an essential task in rational land administration. And let us look at the New South Wales and Ontario solutions to see how to do it in a hurry. Then, perhaps, we will not have to shuffle our feet in shame when another European country demonstrates its system - including tiny Slovenia.

\section{Louis Charlebois}

Gibson Young, solicitors 